This is a pre-print of an article published in International Journal of Science and Matehematics Educacation. The final authenticated version is available online at:

https://doi.org/10.1007/s10763-020-10062-0"

\title{
A learning trajectory as a scaffold for pre-service teachers' noticing of students' mathematical understanding
}

Authors: Ivars, P., Fenández, C. \& Llinares, S.

\begin{abstract}
The objective of this research is to understand how a learning trajectory supports pre-service primary teachers in their noticing of students' mathematical understanding. $A$ total of 95 pre-service primary school teachers used a learning trajectory related to the partwhole meaning of the fraction concept to interpret students' understanding and provide instructional decisions. The findings indicate that the learning trajectory provided preservice teachers with a specific language to describe students' understanding and helped them to notice students' mathematical understanding. Furthermore, the pre-service primary teachers who produced a more detailed discourse also proposed more suitable activities based on students 'understanding. These findings suggest that the learning trajectory can act as a scaffold to notice students' mathematical understanding.
\end{abstract}

Keywords. Children's mathematical understanding, learning trajectory, noticing, pre-service teachers learning.

Teachers have to face simultaneous overlapping situations and interactions in a classroom, hindering their ability to pay attention to all of them. In this context, teachers should know how to effectively focus on the classroom situations or interactions that could potentially enrich students' learning (Mason, 2002; van Es \& Sherin, 2002). In fact, NCTM (2014) points out that teaching effectively implies that a teacher "elicit evidence of students" current mathematical understanding and use it as the basis for making instructional decisions" (p. 53). 
This is a pre-print of an article published in International J ournal of Science and Matehematics Educacation. The final authenticated version is available online at:

https://doi.org/10.1007/s10763-020-10062-0"

From this perspective, effective teaching implies observing students, listening

attentively to their ideas and explanations, planning objectives and using the information to make instructional decisions. Therefore, teachers must develop greater flexibility at recognising students' thinking while they are teaching (van Es \& Sherin, 2002) and must be aware of what happens in their classrooms and how to manage them (Mason, 2002, 2011). In this context, noticing has been conceptualised as the skill of recognising important events in a classroom and giving effective responses (Mason, 1998, 2002).

Previous studies in the field of noticing have centred on what teachers are or are not able to identify as noteworthy events in the classroom (Star \& Strickland, 2008) and how they interpret them (van Es \& Sherin, 2002). Particularly, some of these studies have been focused on noticing student's mathematical understanding: what pre-service teachers are or are not able to attend to regarding students' strategies, interpreting students' understanding and deciding how to respond taking into consideration students' understanding (Jacobs, Lamb, \& Philipp, 2010). Based on the study of Jacobs et al., research has centred on the interrelation between these skills and on how they can be fostered in teacher education programs (Choy, 2016; Authors, 2018a; Authors, 2018b; Schack et al., 2013; Authors, 2015). However, developing noticing skills in teacher education programs represents a challenge without a guide or a framework that can support pre-service teacher noticing (Levin, Hammer, \& Coffey, 2009; Wilson, Mojica, \& Confrey, 2013). In fact, although teachers can learn to identify details of students' answers, they are not always able to use these details to interpret students' understanding or take into consideration their understanding to make instructional decisions (Barnhart \& van Es, 2015).

In this context, recent research has shown that learning trajectories could provide preservice teachers with a structured framework to focus their attention on students' understanding, since it can support them in interpreting students' mathematical understanding 
This is a pre-print of an article published in International J ournal of Science and Matehematics Educacation. The final authenticated version is available online at:

$$
\text { https://doi.org/10.1007/s10763-020-10062-0" }
$$

and in responding with appropriate instruction (Edgington, 2012, 2014; Edgington, Wilson, Sztajn, \& Webb, 2016; Sztajn, Confrey, Wilson, \& Edgington, 2012). In our study, we analyse how the fact of using a learning trajectory as a guide can support pre-service teachers' noticing of students' mathematical understanding.

\section{Theoretical framework}

\section{Noticing students' mathematical understanding}

Mason points out that "noticing is a movement or shift of attention" (Mason, 2011, p. 45) so it implies an increase in sensitivity to the details of the learning situations, avoiding judgements, emotional content and generalities as well as labels (a movement from accounts of to accounting for). Mason distinguishes accounts of in which prospective teachers describe as objectively as possible the situation, and accounting for in which an explanation or theorization can be introduced (as interpretation of the situation). For Mason, people can attend in different ways and he considered five fine-grained processes. Holding wholes, implies attending without considering the details of a situation. Discerning details implies a deeper attention in order to distinguish specific points. The discrimination of the distinguished details allows people to recognise relationships in order to perceive properties than can be used in other situations. Finally, people can reason on the basis of agreed properties avoiding groundless reasoning.

These Mason' micro-level processes of attention can be seen as mechanisms behind the three inter-related skills of noticing students' mathematical understanding: attending to students' strategies, interpreting students' mathematical understanding and deciding how to respond based on students' understandings from the Jacobs and colleagues approach (Jacobs et al., 2010). In fact, the skill of attending to students' answers can be seen as a process of discerning details in students' answers, and interpreting students' understanding as a process 
in which it is possible to recognise relationships and, perceiving properties in students' answers and characteristics of their learning. The skill of deciding how to respond based on students' understanding implies using the information inferred in the interpretation to provide a follow-up activity that can help students progress in their conceptual understanding.

To attend to students' strategies, teachers need to identify mathematical details in students' answers. Interpreting involves coordinating what has been identified (attending to) with what is known about the understanding of a mathematical concept (in other words, adopting a reasoning that is consistent with the research on students' mathematical development). This process implies going beyond knowing the procedures to being able to explain the procedures used by students, interpreting their correctness and explaining the origin of their errors. Therefore, knowledge of how a mathematical concept develops can be useful to interpret students' mathematical understanding. Deciding on the basis of students' understanding requires using knowledge about which aspects of the concept are the easiest or the most difficult for students, which are the most common errors relating to the concept, and which strategies or representations are the most adequate to introduce the concept. Knowledge about how students' mathematical understanding develops over time could also be useful in this process.

\section{Noticing and Learning Trajectories}

A learning trajectory is a construct that involves hypotheses about "the order and nature of the steps in the growth of students' mathematical understanding, and about the nature of the instructional experiences that might support them in moving step by step toward the goals of school mathematics" (Daro, Mosher, \& Corcoran, 2011 p. 12). Learning trajectories offer a reference based on the results of empirical research that can support 
This is a pre-print of an article published in Intemational J ournal of Science and Matehematics

Educacation. The final authenticated version is available online at:

https://doi.org/10.1007/s10763-020-10062-0"

teachers' learning about students' reasoning levels of sophistication in a specific content (Sztajn et al., 2012).

Some studies have shown that when pre-service and in-service teachers used a learning trajectory on equipartition to interpret students' reasoning, they were able to create models of students' thinking (Wilson et al., 2013) or to design lessons for students (Wilson, Sztajn, Edgington, \& Myers, 2015). The results of these studies have shown that the learning trajectory acted as a framework for designing and planning instruction, facilitating the definition of learning objectives and the selection of tasks. In addition, the learning trajectory allowed teachers to anticipate student's responses, and to consider whether the proposed tasks were appropriate to help students progress in their learning. These results support the idea of using learning trajectories to frame students' understanding, connecting theory and practice (Wilson et al., 2015).

From previous research, we hypothesise that providing a learning trajectory (LT) as a guide could help pre-service teachers focus their attention on attending to the mathematical details in the students' answers, on interpreting students' understanding and on deciding how to respond based on students' understanding. In this study, we chose the part-whole meaning of the fraction concept since it is an important concept in primary school education and its teaching and learning has been found to be difficult (Lamon, 2007).

\section{Designing a guide: A LT of the part-whole meaning of the fraction concept}

The COUNTRY curriculum introduces the part-whole meaning of the fraction concept considering different representations. In continuous representations (rectangles, circles, ...), the parts into which the whole is partitioned must have equal area. In discrete representations (set of objects), the parts into which the whole is partitioned must have the same cardinal. In the number line, the parts into which the unit-segment is partitioned must 
This is a pre-print of an article published in International J oumal of Science and Matehematics

Educacation. The final authenticated version is available online at:

https://doi.org/10.1007/s10763-020-10062-0"

have the same length. In this curriculum approach, the use of different representations tries to avoid students' confusion between quantities (referred to area, length, ...) and objects.

However, to go beyond students' confusion, other educators propose measurement models to introduce the fraction concept directing the student's attention to multiplicative relationships between quantities defined in terms of concrete units (Bobos \& Sierpinska, 2017).

Taking into account the COUNTRY context (the use of different representations of the part-whole meaning of fraction), we reviewed previous research on how students' understanding about the part-whole meaning of fraction developed over time (Battista, 2012; Fosnot \& Dolk, 2002; Steffe, 2004; Steffe \& Olive, 2009; van Galen et al., 2008). From these previous studies, we identified two major milestones in students' initial conceptual understanding of the part-whole meaning of the fraction concept. Firstly, the recognition that the parts into which the whole is partitioned must be of equal size but not necessarily of the same shape. Here, we would like to underline that "the parts into which the whole is partitioned must be of equal size" refers to having the same area in a continuous representation or to having the same number (cardinal) in a set of objects in a discrete representation. Secondly, that a part can be divided into other parts which supports the understanding of composite units (for example, see $1 / 4$ as $2 / 8$ or $2 / 8$ as $1 / 4$ ) in continuous and discrete representations.

These two milestones led to identify different proficiency levels in the progression of students' understanding of the part-whole meaning of the fraction concept (Battista, 2012). At level 1 , students are not able to recognise that the parts into which the whole is partitioned must be of equal size; at level 2, students are able to recognise that the parts into which the whole is partitioned must be of equal size (but not necessarily of the same shape) but they are not able to recognise that a part can be divided into other parts. At level 3, students are able to recognise that a part can be divided into other parts. 
This is a pre-print of an article published in Intemational J ournal of Science and Matehematics

Educacation. The final authenticated version is available online at:

https://doi.org/10.1007/s10763-020-10062-0"

The LT consists of the proficiency levels exemplified with different students' answers and examples of learning activities that can support students' transition between levels. For instance, activities for identifying and representing a fraction given a whole, and activities aimed at identifying and representing a whole given a part using different representations: continuous, discrete and the number line.

We were interested in discovering how pre-service primary teachers used this LT to notice students' mathematical understanding. Our research questions were:

- How do pre-service teachers use a student's LT as a tool to interpret students' mathematical understanding?

- How do pre-service teachers make instructional decisions regarding students' mathematical understanding?

\section{Method}

\section{Participants and task}

The participants were 95 pre-service primary school teachers (PTs) in their third of the four years of their primary school teacher degree. They were enrolled in a course with a duration of 150 hours (60/90 face-to-face/distance) related to teaching and learning of mathematics in primary school. The aim of this course was to learn to notice students' mathematical understanding in different mathematical domains (attending to, interpreting and making instructional decisions). One of the mathematical domains was the fraction concept.

Prior to the task reported in this paper, PTs participated in three two-hour sessions where they were introduced to the LT of the part-whole meaning of the fraction concept (given as a theoretical document). Furthermore, they solved fraction activities by identifying the mathematical elements involved and watched and discussed video-clips of primary school students solving fraction activities. The focus of the discussions was students' understanding 
This is a pre-print of an article published in Intemational J ournal of Science and Matehematics Educacation. The final authenticated version is available online at:

https://doi.org/10.1007/s10763-020-10062-0"

using the LT to support their inferences. Then, they completed individually the task reported in this paper.

The task consisted of three primary school students' answers ( $3^{\text {rd }}$ grade students) to an activity of identifying fractions (Figure 1). We used the following questions to guide PTs' noticing, as well as a theoretical document with the LT of the part-whole meaning of the fraction concept.

Q1- Describe the primary school activity taking into account the learning objective: what are the mathematical elements that the student needs to know to solve it?

Q2- Describe how each pair of students has solved the activity identifying how they have used the mathematical elements involved and the difficulties they have had with them. Q3- What are the characteristics of students' understanding (related to the proficiency levels of the LT) that can be inferred from their responses? Explain your answer.

Q4- How would you respond to these students? Propose a learning objective and a new activity to help students progress in their understanding.

The primary school activity of identifying a fraction used in this task (Figure 1) was adapted from Battista (2012) and follows a visual approach to fractions since students have to decide which diagrams in the figure represent three-quarters. In this primary school activity, primary school students had to identify the $3 / 4$ fraction in different representations of the whole: a circle, a rectangle (continuous representations), and a set of little squares (discrete representation). Figures A (circle) and $\mathrm{C}$ (rectangle) do not represent $3 / 4$ considering that the parts into which the whole is partitioned do not have the same area and figures $\mathrm{B}, \mathrm{D}$ and $\mathrm{E}$ (all of them rectangles) and $\mathrm{F}$ (discrete representation: little squares) represent $3 / 4$ since in the continuous representation the parts into which the whole is partitioned have the same area and in the discrete representation, the parts into which the whole is divided (groups of two squares) have the same cardinal. To solve this activity, primary school students had to 
This is a pre-print of an article published in Intemational J ournal of Science and Matehematics Educacation. The final authenticated version is available online at:

https://doi.org/10.1007/s10763-020-10062-0"

recognise two mathematical elements: that the parts into which the whole was partitioned must be of equal size (students have to recognise that figures $\mathrm{A}$ and $\mathrm{C}$ do not represent $3 / 4$ since the parts into which the whole is partitioned are not of equal size), and that a part can be divided into other parts (students have to recognise that Figures E and F-18 squares shaded out of 24 (continuous representation) and 6 little squares shaded out of 8 (discrete representation)- represents $3 / 4$ ).

The answers of the three pairs of primary school students reflected different characteristics of students' understanding (different proficiency levels; Table 1). Xavi and Víctor were not able to identify that the parts into which the whole was partitioned must be of equal size since they considered that figures A, B, C and D represented 3/4. Joan and Tere recognised that the parts into which the whole was partitioned must be of equal size (considering that figures $\mathrm{A}$ and $\mathrm{C}$ do not represent $3 / 4$ ) but they did not recognise that a part can be divided into other parts in continuous and discrete representations (since they say that figure $\mathrm{E}$ is not three quarters because it is divided into 24 equal parts and that 18 are shaded, and that figure F is not a representation of a fraction). Finally, Álvaro and Félix recognised that the parts into which the whole was partitioned must be of equal size (they do not consider $\mathrm{A}$ and $\mathrm{C}$ as $3 / 4$ ), and that a part can be divided into other parts in continuous and discrete representations (they recognise that figures $\mathrm{E}$ and $\mathrm{F}$ represent $3 / 4$ ). 
This is a pre-print of an article published in Intemational J ournal of Science and Matehematics

Educacation. The final authenticated version is available online at:

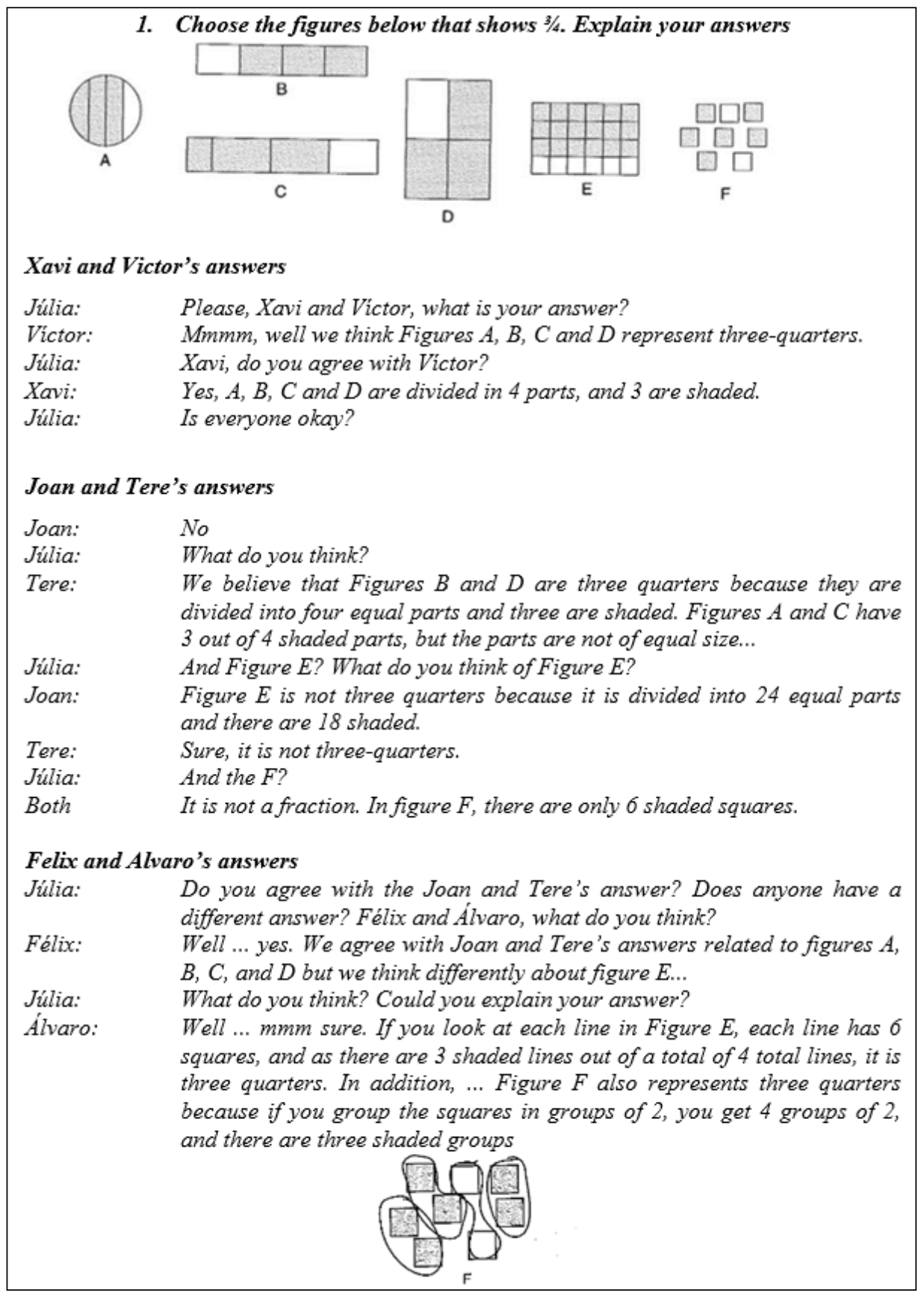

Figure 1. Primary school students' answers to a fraction identification problem showing different proficiency levels.

Table 1

Characteristics of primary school students' answers 
This is a pre-print of an article published in International J ournal of Science and Matehematics Educacation. The final authenticated version is available online at:

https://doi.org/10.1007/s10763-020-10062-0"

\begin{tabular}{|c|c|c|c|}
\hline Mathematical Elements & $\begin{array}{l}\text { Víctor \& Xavi } \\
\text { (level 1) }\end{array}$ & $\begin{array}{l}\text { Joan \& Tere } \\
\text { (level 2) }\end{array}$ & $\begin{array}{l}\text { Félix \& } \\
\text { Álvaro (level } \\
3 \text { ) }\end{array}$ \\
\hline $\begin{array}{l}\text { The parts into which the whole was } \\
\text { partitioned must be of equal size }\end{array}$ & No & Yes & Yes \\
\hline A part can be divided into other parts & No & No & Yes \\
\hline
\end{tabular}

\section{Analysis}

We analysed PTs' answers to the task (Figure 1) according to whether they: (i) identified the mathematical elements in the student's answers; (ii) interpreted the student's understanding considering the characteristics of the LT; and (iii) provided suitable activities that helped students progress in their understanding. We carried out an inductive analysis of the PTs' written discourse in response to the task considering the three points mentioned. In this analysis, a subset of PTs' answers was independently analysed by three researchers. We then compared our results and discussed our discrepancies (triangulation process) until reaching a consensus on how to describe the different categories. Subsequently, new data samples were added in order to revise the categories that emerged.

In relation to the mathematical elements involved in the students' answers identified by PTs, we distinguished three categories according to whether they used the mathematical elements involved in the students' answers: the parts into which the whole is partitioned must be of equal size and a part can be divided into other parts to describe students' answers (Table 2).

Table 2

Categories according to the identification of mathematical elements 
This is a pre-print of an article published in Intemational J ournal of Science and Matehematics

Educacation. The final authenticated version is available online at:

https://doi.org/10.1007/s10763-020-10062-0"

\begin{tabular}{ll}
\hline Categories & Example of PTs'answers \\
\hline $\begin{array}{l}\text { Identification of } \\
\text { both mathematical } \\
\text { elements }\end{array}$ & $\begin{array}{l}\text { The problem with Xavi and Víctor is that they focused only on the } \\
\text { shaded parts without taking into account that the parts into which the } \\
\text { whole is divided must be of equal size (A and D). }\end{array}$ \\
$\begin{array}{l}\text { Regarding figure E, they did not take into account that a part can be } \\
\text { divided into other parts. }\end{array}$
\end{tabular}

Identification of the Víctor and Xavi answered "A, B, C, and D" because they did not element the parts into which the whole is partitioned must be of equal size take into account that the size of the parts had to be equal.

Tere and Joan answered $\mathrm{B}$ and $\mathrm{C}$ because they were aware of the need for the parts to be of equal size, but they did not consider a part as an iterative unit since they did not recognise $\mathrm{E}$ and $\mathrm{F}$ as 3/4.

No identification of the mathematical

Xavi and Víctor identified the unitary fraction in figures B, C, and D elements and that the shaded part is $3 / 4$ while any individual part is $1 / 4$.

Note. Emphasis is added on the mathematical elements identified

With regard to how PTs interpreted students' understanding, we focused on whether they related the mathematical elements identified in students' answers with the characteristics of students' understanding provided in the LT. Four categories emerged from this analysis: PTs who gave non-sense answers and the three categories shown in Table 3. These categories show differences in pre-service primary teachers' discourse.

Table 3

Categories of interpreting students' understanding

\begin{tabular}{|c|c|c|}
\hline Categories & Example of PTs' answers & Analysis \\
\hline $\begin{array}{l}\text { Evidencers. PTs } \\
\text { who interpreted } \\
\text { students' } \\
\text { understanding } \\
\text { providing details } \\
\text { from students' } \\
\text { answers }\end{array}$ & $\begin{array}{l}\text { Xavi and Víctor counted the } \\
\text { shaded parts without taking } \\
\text { into account whether the } \\
\text { parts should be of equal } \\
\text { size. } \\
\text { a. They did not recognise } \\
\text { that the parts of the whole } \\
\text { must be of equal size (when }\end{array}$ & $\begin{array}{l}\text { PT92 related the mathematical } \\
\text { elements identified in the } \\
\text { students' answer with the } \\
\text { proficiency levels of the LT to } \\
\text { interpret students' } \\
\text { understanding, providing details } \\
\text { from students' answers to } \\
\text { support his interpretation (for } \\
\text { instance, when he wrote: "when }\end{array}$ \\
\hline
\end{tabular}


This is a pre-print of an article published in International J oumal of Science and Matehematics Educacation. The final authenticated version is available online at:

https://doi.org/10.1007/s10763-020-10062-0"

\begin{tabular}{|c|c|c|}
\hline \multirow[t]{3}{*}{$\begin{array}{l}\text { (emphasis is added } \\
\text { on the details) }\end{array}$} & $\begin{array}{l}\text { they chose figures } A \text { and } C \\
\underline{\text { as } 3 / 4} \text { ) }\end{array}$ & $\begin{array}{l}\text { they chose figures } A \text { and } C \text { as } \\
3 / 4 ") \text {. }\end{array}$ \\
\hline & $\begin{array}{l}\text { b. They did not recognise } \\
\text { that a part can be divided } \\
\text { into other parts (since they } \\
\text { did not choose figure E and } \\
\text { F as } 3 / 4)\end{array}$ & \\
\hline & $\begin{array}{l}\text { So, taking into account a) } \\
\text { and } b \text { ) they are at level } 1 .\end{array}$ & \\
\hline $\begin{array}{l}\text { Needless. PTs who } \\
\text { interpreted } \\
\text { students' } \\
\text { understanding } \\
\text { providing details } \\
\text { from students' } \\
\text { answers but adding } \\
\text { unnecessary } \\
\text { information } \\
\text { (emphasis is added } \\
\text { on the unnecessary } \\
\text { information) }\end{array}$ & $\begin{array}{l}\text { Xavi and Víctor are at Level } \\
1 \text { since they did not } \\
\text { recognise that the parts of a } \\
\text { whole must be of equal size } \\
\text { when they chose the figures } \\
\text { divided in } 4 \text { parts with } 3 \\
\text { shaded. They had } \\
\text { difficulties in recognising } \\
\text { that a part can be divided } \\
\text { into other parts (E and F) } \\
\text { and they did not take into } \\
\text { account that the wholes } \\
\text { must be of equal size when } \\
\text { they compare fractions. }\end{array}$ & $\begin{array}{l}\text { PT29 related the mathematical } \\
\text { elements identified in the } \\
\text { students' answer with the } \\
\text { proficiency levels of the LT to } \\
\text { interpret students' } \\
\text { understanding, providing details } \\
\text { from the students' answers. } \\
\text { Nevertheless, she added } \\
\text { unnecessary information (when } \\
\text { she wrote: "they did not take } \\
\text { into account that the wholes } \\
\text { must be of equal size when they } \\
\text { compare fractions") }\end{array}$ \\
\hline
\end{tabular}

\begin{tabular}{|c|c|c|}
\hline $\begin{array}{l}\text { Non-evidencers. } \\
\text { PTs who } \\
\text { interpreted } \\
\text { students' } \\
\text { understanding but } \\
\text { did not provide } \\
\text { details from the } \\
\text { students' answers }\end{array}$ & $\begin{array}{l}\text { Víctor and Xavi are at Level } \\
1 \text { since they did not } \\
\text { recognise that the parts of } \\
\text { the whole must be of equal } \\
\text { size and they did not } \\
\text { recognise that a part can be } \\
\text { divided into other parts. }\end{array}$ & $\begin{array}{l}\text { PT03 related the mathematical } \\
\text { elements identified in the } \\
\text { students' answer with the } \\
\text { proficiency levels of the LT to } \\
\text { interpret students' understanding } \\
\text { but did not provide details from } \\
\text { the students' answers (he did not } \\
\text { provide details from students' } \\
\text { answers to support his } \\
\text { inferences. In other words, he } \\
\text { did not explain why Víctor and } \\
\text { Xavi did not recognise that the } \\
\text { parts of a whole must be of } \\
\text { equal size). }\end{array}$ \\
\hline
\end{tabular}

Regarding instructional decisions, we considered whether PTs provided a learning objective to support students' conceptual progression and a suitable activity with this objective (an activity coherent with the learning objective provided to support students' 
This is a pre-print of an article published in International J oumal of Science and Matehematics Educacation. The final authenticated version is available online at:

https://doi.org/10.1007/s10763-020-10062-0"

understanding of the mathematical elements). Two categories emerged from this analysis

(Table 4).

Table 4

Categories of teaching decisions

\begin{tabular}{|c|c|c|}
\hline Categories & Example of PTs' answers & $\begin{array}{l}\text { Evidence from the } \\
\text { analysis }\end{array}$ \\
\hline $\begin{array}{l}\text { PTs who } \\
\text { provided only the } \\
\text { learning objective } \\
\text { or provided an } \\
\text { activity which } \\
\text { was not suitable } \\
\text { for the learning } \\
\text { objective }\end{array}$ & $\begin{array}{l}\text { (PT86) Víctor and Xavi. Objective: } \\
\text { Understanding the idea that the } \\
\text { parts into which the whole is } \\
\text { partitioned must be of equal size. } \\
\text { (PT16) Víctor and Xavi. Objective: } \\
\text { Recognising that the parts into } \\
\text { which the whole is partitioned must } \\
\text { be of equal size. } \\
\text { Activity: Using cut-outs of different } \\
\text { sizes, they must construct different } \\
\text { figures (rectangles, circles...) }\end{array}$ & $\begin{array}{l}\text { PT86 identified a learning } \\
\text { objective (transition from } \\
\text { level } 1 \text { to level 2) but she } \\
\text { did not provide a suitable } \\
\text { activity. } \\
\text { Although PT16 outlined a } \\
\text { learning objective } \\
\text { (transition from level } 1 \text { to } \\
\text { level 2), she proposed an } \\
\text { activity with manipulatives } \\
\text { that was not clearly related } \\
\text { to fractions. }\end{array}$ \\
\hline
\end{tabular}

PTs who provided the learning objective and a suitable activity for this learning objective
(PT88) Xavi and Víctor: Objective: Recognising that the parts of a whole must be of equal size.

Activity: Working with a square sheet of paper and asking the students to represent $1 / 2$ in different ways.
The PT88 provided a learning objective (recognising that the parts of a whole must be of equal size to support students' conceptual progression) and a suitable activity with this objective.

The activity proposed involves the mathematical element "the parts of the whole must be of equal size" since students have to represent $1 / 2$ in different ways. So this activity is suitable for the learning objective provided.

(PT46) Xavi and Víctor: Objective: Recognising that the parts of the whole must be of equal size.

Activity: Which one represents $1 / 2$ ?
The PT46 proposed a suitable activity consisting in identifying fractions in which different 


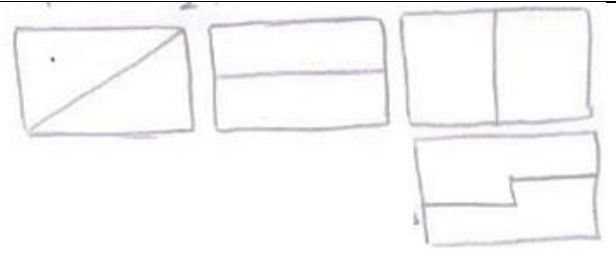

(PT61) Joan and Tere are at level 2 so their objective is to recognise that a part can be divided into other parts. The activity: Shade 2/4 of the following figures
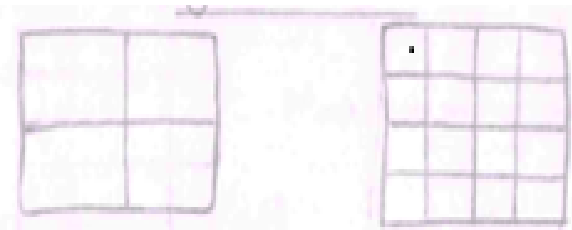

representations of $1 / 2$ were given.

PT61 proposed a suitable activity consisting in representing fractions considering their difficulties in understanding that "a part can be divided into other parts". The activity focuses on identifying $2 / 4$ in different figures, particularly in the second figure, students have to identify that 8 squares shaded out of 16 represents $2 / 4$.

\section{Results}

Two significant results stood out after analysing the data. Firstly, PTs interpreted students' understanding using the LT, but they differed in the amount of details they provided to support their interpretations. Secondly, PTs who provided details to support their interpretations of students' understanding seemed to provide more suitable activities to support students' conceptual progression.

\section{Different ways of interpreting students' understanding}

A total of two out of the 95 PTs did not identify the mathematical elements in students' answers and three were able to identify only the mathematical element the parts into which the whole is partitioned must be of equal size. The other 90 PTs described students' answers using the two mathematical elements: the parts into which the whole is partitioned must be of equal size and a part can be divided into other parts. Moreover, 89 out of these 90 
This is a pre-print of an article published in International J ournal of Science and Matehematics

Educacation. The final authenticated version is available online at:

https://doi.org/10.1007/s10763-020-10062-0"

PTs were able to interpret students' mathematical understanding. However, we identified three ways in which PTs interpreted students' understanding using the LT according to the details provided in the generated discourse: non-evidencers, needless and evidencers.

Non-evidencers. These PTs interpreted students' understanding relating the mathematical elements identified in students' answers with the characteristics of the LT but did not provide details from the students' answers to support their interpretations (23 PTs). For instance, PT85 wrote:

Pair 1 (Xavi and Víctor)

They do not use the mathematical elements of fractions because they do not assume that the parts of the whole must be of equal size. Moreover, they do not recognise that a part can be divided into other parts. So these students are at level 1 of the Learning Trajectory.

Pair 2 (Tere and Joan)

They identify that the parts of the whole must be of equal size, but they have difficulties in recognising that a part can be divided into other parts. So these students are at level 2 of the Learning Trajectory.

Pair 3 (Félix and Álvaro)

Like Tere and Joan [the second pair of primary school students], they identify that the parts of a whole must be of equal size and recognise that a part can be divided into other parts. So these students are at level 3 of the Learning Trajectory.

This pre-service teacher produced a discourse to interpret students' understanding using the mathematical elements the parts of the whole must be of equal size and a part can be divided into other parts and related them with the proficiency levels of the LT. In other words, he interpreted students' understanding considering the LT. However, he did not 
This is a pre-print of an article published in Intemational J oumal of Science and Matehematics Educacation. The final authenticated version is available online at:

https://doi.org/10.1007/s10763-020-10062-0"

provide details from students' answers to support his interpretation. For example, he did not explain why Xavi and Víctor did not recognise that a part can be divided into other parts.

Needless. These PTs interpreted students' understanding relating the mathematical elements identified in students' answers with the characteristics of the LT and provided details from the students' answers but adding unnecessary information (7 PT). For instance, the PT62 wrote:

\section{Pair 1 (Xavi and Víctor) $\rightarrow$ Level 1}

This pair has difficulties in recognising that the parts of the whole must be of equal size because they only count the shaded parts in each figure. They do not recognise that a part can be divided into other parts since they believe that figure E represents $3 / 4$. Moreover, in figure C, they do not notice that the parts are not equally sized.

This pre-service teacher interpreted students' understanding providing details from the students' answers. For instance, she wrote “...they only count the shaded parts in each figure"; "...they believe that figure E represents $3 / 4$ "; “... (in) figure $C$ they do not notice that the parts are not equally sized". Nevertheless, she added unnecessary information when she interpreted students' understanding of pairs 2 and 3 (emphasis is added on the unnecessary information provided):

Pair 2 (Tere and Joan) $\rightarrow$ Level 2

This pair has difficulties in recognising that a part can be divided into other parts, but they have assimilated that the parts of the whole must be of equal size. When they compare fractions, they recognise that the wholes must be equal.

PT62 supported her inference (of pair 2) mentioning an activity consisting in comparing fractions and underlining the necessity of identifying that the wholes must be equal, that was unnecessary in this case (an activity of identifying a fraction). 
This is a pre-print of an article published in International J oumal of Science and Matehematics Educacation. The final authenticated version is available online at:

https://doi.org/10.1007/s10763-020-10062-0"

Pair 3 (Félix and Álvaro) $\rightarrow$ Level 3

They identify and represent fractions in discrete contexts recognising that the groups must be of equal size. At the same time, they recognise that a part can be divided into other parts. Finally, when comparing fractions, they recognise that the wholes must be equal and they establish the inverse relation between the number of parts and the size of each part.

In the same way, when she described Felix and Alvaro's answer, she also mentioned a fraction comparison activity that is not necessary. The PTs of this group produced a discourse, adding information that was not necessary in the interpretation of students' understanding.

Evidencers. This group of PTs interpreted students' understanding relating the mathematical elements identified in students' answers with the characteristics of the LT and provided details from students' answers (59 PT). They interpreted students' understanding and strengthened their interpretation using observable details of the students' answers. For instance, PT51 wrote (emphasis is added on the details provided from students' answers):

Pair 1 (Xavi and Víctor)

They say that $3 / 4$ are represented in figures A, B, C, and D because they believe that they have to find a whole divided into four parts. They do not take into account that the parts of the whole must be of equal size ( $\mathrm{A}$ and $\mathrm{C}$ are incorrect) . They do not identify either that a part can be divided into other parts in continuous or discrete contexts (Figure F). So they are at Level 1 because they do not recognise that the parts of the whole must be of equal size.

Pair 2 (Joan and Tere)

They explain that figures B and D are $3 / 4$ because they are divided into four equal parts and three of them are shaded. So they recognise that the parts of the whole must be of equal size. 
This is a pre-print of an article published in International J oumal of Science and Matehematics Educacation. The final authenticated version is available online at:

https://doi.org/10.1007/s10763-020-10062-0"

They indicate that figure $\mathrm{F}$ is not $3 / 4$ because there are six shaded squares, so they are at level 2 because they do not recognise that a part can be divided into other parts. On the contrary, they count squares and they do not recognise $3 / 4$ in this context (equivalence with figures $\mathrm{E}$ and $\mathrm{F}$ ).

Pair 3 (Félix and Álvaro)

These students reason about figures A, B, C, D in the same way as Joan and Tere. However, in figure $E$, as the whole has 6 equal squares in each line and there are 3 lines out of 4 shaded, they say that this figure represents $3 / 4$. And, in figure F, they group the eight squares in groups of 2 , obtaining 4 groups of 2 squares each. Then they realise that 3 groups of 2 squares are shaded. They are at level 3 because they recognised that a part can be divided into other parts.

The ways of interpreting students' understanding differed in the discourse generated by pre-service primary teachers. The non-evidencers generated a less detailed discourse without giving details from students' answers to support their interpretations, needless used a more detailed discourse giving details from students' answers but adding unnecessary information and, evidencers generated a detailed discourse giving details from students' answers. Furthermore, our results show that when PTs provided a more detailed discourse, they seemed to be able to provide more suitable activities to promote the students' conceptual progression.

\section{Features of PTs' discourse and the activities provided}

After interpreting students' understanding, PTs had to propose an activity (including the learning objective) to each pair of students to help them progress in their understanding (one activity for each pair of primary students). Table 5 shows the number of activities proposed (and percentages taking into account the number of possible activities they could provide) by each of the three groups (non-evidencers, needless and evidencers). Table 5 displays the relation between the way of interpreting students' understanding (nonevidencers, needless and evidencers) with the number of suitable activities proposed to each 
This is a pre-print of an article published in International J ournal of Science and Matehematics Educacation. The final authenticated version is available online at:

https://doi.org/10.1007/s10763-020-10062-0"

pair of students (Xavi and Víctor-from level 1 to level 2; Joan and Tere- from level 2 to level 3; so there was a total of 2 activities $\times 89$ PTs). PTs did not propose activities to Félix and Álvaro since they considered that these students had understood the two mathematical elements considered.

Table 5

Activities proposed in relation to the way PTs interpreted students' understanding

\begin{tabular}{|c|c|c|c|c|c|c|c|}
\hline & & \multicolumn{2}{|c|}{$\begin{array}{l}\text { From Level } 1 \text { to Level } 2 \\
\text { (Xavi and Víctor) } \\
\text { Learning objective: } \\
\text { Understanding "the parts } \\
\text { into which the whole is } \\
\text { partitioned must be of } \\
\text { equal size" }\end{array}$} & \multicolumn{2}{|c|}{$\begin{array}{l}\text { From Level } 2 \text { to Level } 3 \\
\text { (Joan and Tere) } \\
\text { Learning objective: } \\
\text { Understanding "a part } \\
\text { can be divided into other } \\
\text { parts" }\end{array}$} & \multirow{2}{*}{$\begin{array}{c}\text { Total } \\
\begin{array}{c}\text { Number of } \\
\text { activities }\end{array}\end{array}$} & \multirow{2}{*}{$\begin{array}{c}\text { Total } \\
\\
\%\end{array}$} \\
\hline & PTs & $\begin{array}{l}\text { Number of } \\
\text { activities }\end{array}$ & $\%$ & $\begin{array}{l}\text { Number of } \\
\text { activities }\end{array}$ & $\%$ & & \\
\hline $\begin{array}{l}\text { Non- } \\
\text { evidencers }\end{array}$ & 23 & 3 & $13 \%$ & 8 & $35 \%$ & 11 & $24 \%$ \\
\hline Needless & 7 & 3 & $43 \%$ & 2 & $29 \%$ & 5 & $36 \%$ \\
\hline Evidencers & 59 & 26 & $44 \%$ & 38 & $64 \%$ & 64 & $54 \%$ \\
\hline Total & 89 & 32 & $36 \%$ & 48 & $54 \%$ & 80 & $45 \%$ \\
\hline
\end{tabular}

PTs were asked to propose two possible activities, one to help Xavi and Víctor to understand "the parts into which the whole is partitioned must be of equal size" and another to help Joan and Tere to understand the mathematical element "a part can be divided in other parts". Table 5 shows that 23 PTs from the group of non-evidencers, who interpreted students' understanding but did not provide details from the students' answers, proposed 11 suitable activities out of 46 possible activities ( 2 possible activities $\times 23$ PTs in this group). They were able to propose three activities from level 1 to level 2 and eight activities from level 2 to level 3. Therefore, the non-evidencers proposed a suitable activity in $24 \%$ of the situations. 
This is a pre-print of an article published in Intemational J oumal of Science and Matehematics Educacation. The final authenticated version is available online at:

https://doi.org/10.1007/s10763-020-10062-0"

The seven PTs of the group of needless, who interpreted students' understanding providing details from the students' answers but adding unnecessary information, proposed five suitable activities out of 14 possible activities ( 2 possible activities $\times 7$ PTs in this group). These PTs proposed three activities addressed to understand "the parts into which the whole is partitioned must be of equal size" (from level 1 to level 2) and two addressed to understand "a part can be divided into other parts" (from level 2 to level 3), therefore they proposed a suitable activity in $36 \%$ of cases. Finally, the 59 PTs of the group of evidencers, who interpreted students' mathematical understanding providing details from students' answers, proposed a suitable activity in $54 \%$ of the situations $(2$ activities $\times 59$ PTs in this group, they proposed 64 out of 118 possible activities; 26 from level 1 to level 2 and 38 from level 2 to level 3).

These data suggest that when PTs generated a more detailed discourse providing evidence from students' answers (evidencers), they were in a better position to provide a suitable activity to support students' conceptual progress. In fact, non-evidencers had more difficulties in providing suitable activities to support students' conceptual progress (only in $24 \%$ of the situations) than evidencers (in $54 \%$ of the cases).

Furthermore, Table 5 shows that PTs in the groups of non-evidencers and evidencers had more difficulties in proposing activities to help students understand the mathematical element "the parts into which the whole is partitioned must be of equal size" than to understand the mathematical element "a part can be divided into other parts" (non-evidencers $13 \%$ vs $35 \%$ and evidencers $44 \%$ vs $64 \%$ ).

Table 6 shows the number of PTs who proposed one or both activities (Xavi and Víctor - an activity from Level 1 to Level 2; Joan and Tere - an activity from Level 2 to Level 3). A total of 57 out of the 89 PTs (64\%) who interpreted students' understanding 
This is a pre-print of an article published in Intemational J ournal of Science and Matehematics Educacation. The final authenticated version is available online at:

https://doi.org/10.1007/s10763-020-10062-0"

proposed at least one suitable activity to support students' conceptual progress. A total of 9 out of 23 PTs of the non-evidencers group proposed at least one activity to help students progress in their mathematical understanding, in contrast with 45 out of the 59 PTs who did in the evidencers group (39\% vs 76\% respectively). Only two PTs ( $9 \%$ ) of the non-evidencers group provided both activities while in the evidencers group, 19 provided both activities (32\%). These data show that 14 out of the 23 non-evidencers and 11 out of the 59 evidencers provided only one learning objective without proposing an activity. This result seems to suggest the fact that when PTs generated a more detailed discourse (giving evidence from students' answers to support their interpretations), they could propose more suitable activities to support students' conceptual progress.

Table 6

Number of PTs who proposed one or both activities

\begin{tabular}{cccccc}
\hline Blank & $\begin{array}{c}\text { Only } \\
\text { objectives }\end{array}$ & $\begin{array}{c}\text { Only one } \\
\text { activity from } \\
\text { Level 1 to } \\
\text { Level 2 }\end{array}$ & $\begin{array}{c}\text { Only one } \\
\text { activity from } \\
\text { Level 2 to } \\
\text { Level 3 }\end{array}$ & $\begin{array}{c}\text { Both } \\
\text { activities }\end{array}$ & TOTAL \\
2 & 2 & 1 & 6 & 2 & 23 \\
3 & 14 & 1 & 0 & 2 & 7 \\
5 & 27 & 9 & 19 & 19 & 59 \\
\hline
\end{tabular}

\section{Discussion and conclusions}

The aim of this study was to analyse how pre-service primary teachers use a LT to notice students' mathematical understanding related to the part-whole meaning of the fraction concept. Our findings indicate that (i) the LT of the part-whole meaning of the fraction concept acted as a scaffold to support PTs' noticing of students' mathematical understanding, allowing to generate a detailed discourse about students' understanding and, (ii) PTs who 
This is a pre-print of an article published in International J ournal of Science and Matehematics

Educacation. The final authenticated version is available online at:

https://doi.org/10.1007/s10763-020-10062-0"

provided a more detailed discourse were able to provide more suitable activities based on students' understanding.

\section{The LT as a scaffold to support PTs' noticing of students' mathematical understanding}

The fact that 89 out of 95 PTs interpreted students' understanding using characteristics of the LT and that 57 out of the 89 PTs (64\%) who interpreted students' understanding proposed a suitable activity to support students' conceptual progress suggests that the theoretical information (the LT) and the task design in the learning environment provided PTs with a guide to talk about students' mathematical understanding and to provide activities focused on students' conceptual understanding.

Our results provide us with a snapshot of how the use of a LT supports PTs in interpreting students' mathematical understanding and how it also helps them to provide a follow up with suitable activities. These findings indicate that the LT acts as scaffold to support PTs' noticing of students' mathematical understanding. This result is in line with the results of other studies which indicate that information about learning trajectories of specific topics supports the generation of a professional discourse (Edington et al., 2016), and that the use of a framework to guide the interpretation supports PTs' noticing (Levin et al., 2009; Wilson et al., 2013).

Furthermore, our results also show that these 89 PTs interpreted students' mathematical understanding using the students' LT in three different ways, differing in the more or less detailed discourse they generated: (i) Non-evidencers: PTs who related the mathematical elements identified with the characteristics of the LT, but did not provide details on students' answers leading to a less detailed discourse; (ii) Needless : PTs who related the mathematical elements with the characteristics of the LT and provided details from the students' answers but added unnecessary information or information not provided in the 
This is a pre-print of an article published in International J oumal of Science and Matehematics Educacation. The final authenticated version is available online at:

https://doi.org/10.1007/s10763-020-10062-0"

students' answers and; (iii) Evidencers: PTs who related the mathematical elements with the characteristics of the LT and provided details from students' answers thus producing a detailed discourse. We would like to underline that we do not see a progression in these categories since "absence of evidence, is not evidence of absence" (Mason, 2017, p. 14). In other words, the fact that PTs did not use the details of students' answers cannot be seen as an evidence of not attending them. Nevertheless, the varying discourses generated by PTs showed how some of them had difficulties in providing details from students' answers to support their interpretations. This result is important since PTs who generated a more detailed discourse to interpret students' mathematical understanding proposed more suitable activities taking into account students' understanding.

\section{From a more detailed discourse to providing activities based on students' understanding}

Our results suggest a relationship between the way in which PTs interpreted students' mathematical understanding relating to the part-whole meaning of the fraction concept and the activities provided since PTs who produced a more mathematical detailed discourse to interpret students' understanding proposed more suitable activities according to students' understanding. Therefore, we can see the value of details in the mathematical discourse "as a major learning outcome in its own right" (Clarke, 2013, p. 22) since "the more sensitive you are to noticing details, the more tempted you are likely to be to act responsively" (Mason, 2002, p. 248). Consequently, one of the defining elements of enhanced noticing may consist in the production of a detailed discourse. Our results seem to suggest that a detail-sensitive discourse leads PTs to a more attentive focus on students' understanding and prepares them to make instructional decisions based on students' mathematical understanding. Therefore, the LT helped PTs direct their attention, leading them to give accounts of the teaching-learning situations, focusing “on particulars, on details, and so helps in avoiding generalities and labels, which [...] can block access to alternative paths, alternative interpretations, and so 
This is a pre-print of an article published in International J oumal of Science and Matehematics Educacation. The final authenticated version is available online at:

https://doi.org/10.1007/s10763-020-10062-0"

ultimately, to alternative acts" (Mason, 2002, p. 51). When PTs generate accounts of the situation (providing details), they are in better conditions of accounting for the situation.

Regarding the activities proposed by PTs, results showed that they had more difficulties in proposing activities to help students understand the mathematical element "the parts into which the whole is partitioned must be of equal size" than to understand the mathematical element "the part can be divided into other parts". This difference seems to indicate that each mathematical element demands specific knowledge to propose a suitable activity and that the lack of knowledge "narrowed the scope of what was possible" (Kahan, Cooper, \& Bethea, 2003; p. 247). This result suggests that noticing is a complex and specialized process (Mason, 2002; Sherin, Jacobs, \& Philipp, 2011; Simpson \& Haltiwagner, 2017) and that it can be influenced by several factors such as: mathematical pedagogical knowledge (Schoenfeld, 2011; Stürmer, Könings, \& Seidel, 2013; Stürmer, \& Seidel, 2017); prior experience (Erickson, 2011); context (Coles, 2013; Mitchell \& Marin, 2015); or beliefs (Shoenfeld, 2011; Wessels, 2018).

\section{Implications for teacher education}

One of the objectives of research on learning trajectories is to make LTs into usable tools for teachers (Daro et al., 2011). To do so, mathematics teacher educators must "use their understandings of the goals and context of both the research and teaching communities to represent findings from research in ways that are meaningful and useful for teachers" (Edgington et al., 2016). This way of working (transforming learning trajectories into usable tools for teachers) has special implications in our present context in which PTs have little opportunity to put their theoretical knowledge into practice in teaching situations. Although the program includes a period of practices at schools in which PTs have to design and teach a lesson, PTs can select the subject they teach and few choose mathematics. In this context, the 
This is a pre-print of an article published in International J oumal of Science and Matehematics Educacation. The final authenticated version is available online at:

https://doi.org/10.1007/s10763-020-10062-0"

LT provides them with a structure within which they can start to theorise in practice (Smith, 2003) when attending to, interpreting and deciding how to respond.

As highlighted by previous research, noticing students' mathematical understanding is a skill that is developed and sustained over long periods of time, effort and experience (Little, 1993; van Es \& Sherin, 2008), and through direct classroom teaching experience (Jacobs et al., 2010). Therefore, teacher education programs must focus on practice. In other words, teacher educators need to create spaces for PTs to develop ways of learning how to frame and describe what they are observing to make conjectures, "how to bring evidence to bear on them, how to weigh the often-conflicting information they get, to make well-supported judgments" (Ball \& Cohen, 1999, p. 16). Nevertheless, focusing on practice does not necessarily mean learning in real situations (Ball \& Cohen, 1999). This can be achieved by selecting or designing materials using students' written answers or student video-clips. In our study, we can consider that PTs did learn from practice since they started to use the LT (information regarding students' understanding) to notice students' mathematical understanding in the designed task.

Our results suggest that the designed task and the information on students' mathematical understanding organized within a LT played an important part in scaffolding noticing. More specifically, the type of task used in this research and the LT seem to have represented powerful tools. They helped PTs focus their attention on students' mathematical understanding and generate information to provide suitable activities based on students' understanding. Furthermore, the LT seems to have been an efficient tool to improve PTs' mathematical discourse as it provided them with a specific language to describe students' understanding. 
This is a pre-print of an article published in International J oumal of Science and Matehematics Educacation. The final authenticated version is available online at:

https://doi.org/10.1007/s10763-020-10062-0"

Furthermore, our findings regarding the different ways PTs interpreted students'

mathematical understanding according to the more or less detailed discourse they produced (evidencers, non-evidencers and needless) may represent a relevant contribution to teacher education programs: these profiles can be used as a means to assess PTs' noticing and teacher educators can use them to support PTs in developing their noticing competence. However, we are concerned that we cannot generalize our results and more research is necessary to analyse how PTs' noticing skills develop when they take part in a learning environment that uses a students' LT as a scaffold.

\section{References}

Authors (2015). International Journal of Science and Mathematics Education

Authors (2018a). Chapter in Edited Book. Springer

Authors (2018b). EURASIA Journal of Mathematics, Science and Technology Education

Ball, D. L., \& Cohen, D. (1999). Developing practice, developing practitioners: Toward a practice-based theory of professional education. In L. Darling-Hammond, \& G. Sykes (Eds.), Teaching as the learning profession (pp. 3-32). San Francisco, CA: JosseyBass.

Barnhart, T., \& van Es, E. (2015). Studying teacher noticing: Examining the relationship among pre-service science teachers' ability to attend, analyze and respond to student thinking. Teaching and Teacher Education, 45, 83-93. doi: 10.1016/j.tate.2014.09.005

Battista, M.T. (2012). Cognition-Based Assessment and teaching of fractions: Building on students' reasoning. Portsmouth, N.H. Heinemann.

Bobos, G. \& Sierpinska, A. (2017). Measurement approach to teaching fractions: A design experiment in a preservice course for elementary teachers. International Journal of Mathematics Teaching and Learning, 18(2), 203-239. http://www.cimt.org.uk/ijmtl/index.php/IJMTL/article/view/65/34

Choy, B.H. (2016). Snapshots of mathematics teacher noticing during task design. Mathematics Education Research Journal, 28(3), 421-440. doi: 10.1007/s13394-016$\underline{0173-3}$

Clarke, D. J. (2013). Contingent conceptions of accomplished practice: the cultural specificity of discourse in and about the mathematics classroom. ZDM Mathematics Education, 45(1), 21-33. doi: 10.1007/s11858-012-0452-8

Coles, A. (2013). Using video for professional development: the role of the discussion facilitator. Journal of Mathematics Teacher Education, 16(3), 165-184. doi: $\underline{10.1007 / \mathrm{s} 10857-012-9225-0}$ 
Daro, P., Mosher, F., \& Corcoran, T. (2011). Learning trajectories in mathematics: A foundation for standards, curriculum, assessment, and instruction. CPRE Research Report \#RR-68. Philadelphia: Consortium for Policy Research in Education. doi: 10.12698/cpre.2011.rr68

Edgington, C. P. (2012). Teachers' uses of a Learning Trajectory to support attention to students' mathematical thinking (Doctoral dissertation). Retrieved from https://search.proquest.com/docview/1346014792

Edgington, C. (2014). Teachers' use of a Learning Trajectory as a tool for Mathematics Lesson Planning. In J.J. Lo, K. Leatham, \& L.van Zoest (Eds.), Research Trends in Mathematics Teacher Education, (pp.261-284). Cham, Switzerland: Springer. doi: 10.1007/978-3-319-02562-9 14

Edgington, C., Wilson, P.H., Sztajn, P., Webb, J. (2016). Translating Learning Trajectories into useable tools for teachers. Mathematics Teacher Educator, 5(1), 65-80. doi: $\underline{10.5951 / \text { mathteaceduc.5.1.0065 }}$

Erickson, F. (2011). On noticing teacher noticing. In M. G. Sherin, V.R. Jacobs, \& R.A. Philipp (Eds.), Mathematics teacher noticing: Seeing through teachers' eyes, (pp.1734). New York: Routledge.

Fosnot, C. T., \& Dolk, M. (2002). Young mathematicians at work, 3: Constructing fractions, decimals, and percents. Portsmouth: Heinemann.

Jacobs, V.R., Lamb, L.C., \& Philipp, R. (2010). Professional noticing of children's mathematical thinking. Journal for Research in Mathematics Education, 41(2), 169202.

Kahan, J. A., Cooper, D. A., \& Bethea, K. A. (2003). The role of mathematics teachers' content knowledge in their teaching: A framework for research applied to a study of student teachers. Journal of Mathematics Teacher Education, 6(3), 223-252. doi: 10.1023/A:1025175812582

Lamon, S. J. (2007). Rational numbers and proportional reasoning: Toward a theoretical framework. In F. Lester (Ed.), Second handbook of research on mathematics teaching and learning (pp. 629-668). Charlotte, NC: Information Age Publishing.

Levin, D. M., Hammer, D., \& Coffey, J. E. (2009). Novice teachers' attention to student thinking. Journal of Teacher Education, 60(2), 142-154. doi: $\underline{10.1177 / 0022487108330245}$

Little, J. W. (1993). Teachers' professional development in a climate of educational reform. Educational Evaluation and Policy Analysis, 15(2), 129-151. doi: $\underline{10.3102 / 01623737015002129}$

Mason, J. (1998). Enabling teachers to be real teachers: Necessary levels of awareness and structure of attention. Journal of Mathematics Teacher Education, 1(3), 243-267. doi: 10.1023/A:1009973717476

Mason, J. (2002). Researching your own practice. The discipline of noticing. London: Routledge-Falmer. doi: 10.4324/9780203471876

Mason, J. (2011). Noticing: roots and branches. In M. G. Sherin, V.R. Jacobs, \& R. A. Philipp (Eds.) Mathematics teacher noticing: Seeing through teachers'eyes. (pp.35-50). New York: Routledge. 
Mason, J. (2017). Proving beneath the surface of experience. In E. O. Schack, M. H. Fisher, \& J. A. Wilhelm (Eds.), Teacher Noticing: Bridging and broadening perspectives, contexts, and frameworks (pp. 49-72). Cham: Springer. doi: 10.1007/978-3-319$\underline{46753-5 \quad 1}$

Mitchell, R. N., \& Marin, K. A. (2015). Examining the use of a structured analysis framework to support prospective teacher noticing. Journal of Mathematics Teacher Education, 18(6), 551-575. doi: 10.1007/s10857-014-9294-3

National Council of Teachers of Mathematics (2014). Principles to actions: Ensuring mathematics success for all. Reston, VA: NCTM.

Schack, E. O., Fisher, M. H., Thomas, J. N., Eisenhardt, S., Tassell, J., \& Yoder, M. (2013). Prospective elementary school teachers' professional noticing of children's early numeracy. Journal of Mathematics Teacher Education, 16(5), 379-397. doi: $\underline{10.1007 / \mathrm{s} 10857-013-9240-9}$

Schoenfeld, A. H. (2011). Noticing matters. A lot. Now what. In M. G., Sherin, V. R., Jacobs, \& R. A. Philipp, (Eds.), Mathematics teacher noticing: Seeing through teachers'eyes, (pp. 223-238). New York: Routledge.

Sherin, M.G., Jacobs, V.R., \& Philipp, R.A. (Eds.) (2011). Mathematics Teacher Noticing: Seeing Through Teachers' Eyes. New York: Routledge. doi: 10.4324/9780203832714

Simpson, A., \& Haltiwanger, L. (2016). "This is the First Time I've Done This": Exploring secondary prospective mathematics teachers' noticing of students' mathematical thinking. Journal of Mathematics Teacher Education, 20(4), 335-355. doi: $\underline{10.1007 / \mathrm{s} 10857-016-9352-0}$

Smith, T. (2003). Connecting theory and reflective practice through the use of personal theories. In N. Pateman, B. Dougherty, \& J. Zilliox (Eds.), Proceedings of the 27th Conference of the International Group for the Psychology of Mathematics Education (Vol. 4, pp. 215-222). CRDG, College of Education, University of Hawai: PME.

Star, J. R., \& Strickland, S. K. (2008). Learning to observe: Using video to improve preservice mathematics teachers' ability to notice. Journal of Mathematics Teacher Education, 11(2), 107-125. doi: 10.1007/s10857-007-9063-7

Steffe, L. P. (2004). On the construction of learning trajectories of children: The case of commensurate fractions. Mathematical Thinking and Learning, 6(2), 129-162. doi: $\underline{10.1207 / \mathrm{s} 15327833 \mathrm{mt} 10602 \text { _ } 4}$

Steffe, L., \& Olive, J. (2009). Children's fractional knowledge. Springer Science \& Business Media. doi: 10.1007/978-1-4419-0591-8

Stürmer, K., Könings, K. D., \& Seidel, T. (2013). Declarative knowledge and professional vision in teacher education: Effect of courses in teaching and learning. British Journal of Educational Psychology, 83(3), 467-483. doi: 10.1111/j.2044-8279.2012.02075.x

Stürmer, K., \& Seidel, T. (2017). A Standardized Approach for Measuring Teachers' Professional Vision: The Observer Research Tool. In E. O. Schack, M. H. Fisher, \& J. A. Wilhelm (Eds.), Teacher Noticing: Bridging and broadening perspectives, contexts, and frameworks (pp. 359-380). Cham: Springer. doi: 10.1007/978-3-319-46753-5_21

Sztajn, P., Confrey, J., Wilson, P. H., \& Edgington, C. (2012). Learning trajectory based instruction toward a theory of teaching. Educational Researcher, 41(5), 147-156. doi: $10.3102 / 0013189 \times 12442801$ 
Van Es, E. A., \& Sherin, M. G. (2002). Learning to notice: Scaffolding new teachers' interpretations of classroom interactions. Journal of Technology and Teacher Education, 10(4), 571-595.

Van Es, E. A., \& Sherin, M. G. (2008). Mathematics teachers" "learning to notice" in the context of a video club. Teaching and Teacher Education, 24(2), 244-276. doi: $\underline{10.1016 / \mathrm{j} . \text { tate } .2006 .11 .005}$

Van Galen, F., Feijs, E., Figueiredo, N., Gravemeijer, K., van Herpen, E., \& Keijzer, R. (2008). Fractions, percentages, decimals and proportions: A learning-teaching trajectory for grade 4, 5 and 6. Rotterdam: Sense Publishers.

Wessels, H. (2018). Noticing in Pre-service Teacher Education: Research Lessons as a Context for Reflection on Learners' Mathematical Reasoning and Sense-Making. In G. Kaiser, H. Forgasz, M. Graven, A. Kuzniak, E. Simmt, \& B. Xu (Eds.), Invited Lectures from the 13th International Congress on Mathematical Education (pp. 731748). Cham: Springer. doi: 10.1007/978-3-319-72170-5 41

Wilson, P. H., Mojica, G. F., \& Confrey, J. (2013). Learning trajectories in teacher education: Supporting teachers' understandings of students' mathematical thinking. The Journal of Mathematical Behavior, 32(2), 103-121. doi: 10.1016/j.jmathb.2012.12.003

Wilson, P. H., Sztajn, P., Edgington, C., \& Myers, M. (2015). Teachers' uses of a learning trajectory in student-centered instructional practices. Journal of Teacher Education, 66(3), 227-244. doi:10.1177/0022487115574104 